\title{
Health Services Workforce in Rural China: Baseline Description
}

\author{
Zhao Shuliang \\ School of Public Management, Yunnan University of Finance and Economics , Kunming, P.R.China 650221 \\ ( E-mail:pingyuanzhaosan@163.com )
}

\begin{abstract}
This researchtried to reveal the current situation and to track the future trends of the rural health workforce. By stratified multistage cluster sampling processes, the baseline data of nationwide longitudinal survey were gathered from China. The well-trained interviewers and strict procedures were adopted to ensure the quality of this survey. It is founded that resources for health in rural China are facing problems of aging, gender imbalance, less-educated, and lack of social protection, which calls for special policy to solve these defects in order to achieve the goals of China's latest health care reform.
\end{abstract}

Keywords: health service, Human resource, village doctor

\section{Introduction}

Though some paper discussed the development, the quantity, quality and distribution of China's human resource for health[1,2], Health workforce in the rapidly changing China did not get the deserved attentions. China is experiencing healthcare reform since the central government established series of healthcare policies to meet the citizens revealing demand for an equitable, affordable, and efficient health system[3]. This reform had already drawn the worldwide attentions both from the government and the academicals sphere. Due to the huge population, China was lack of efficient health workers to provide healthcare service to the rural residents [4]. This article try to describe current situation and to track the future trends of the rural health workforce including the village doctors in the village clinics and health workers in the township health centers. While this article mainly focuses the research design and baseline characteristics of village doctors, whose former name is barefoot doctor, beginning at 1960s, performing as the bottom of China's three-tiered health system, providing primary health care and public health services for rural residents $[5,6]$.

\section{Methods}

We selected 4 either east or west provinces or municipality (Jiangsu Province (east), Sichuan Province (west), Gansu Province (west) and Chongqing Municipality (middle west)) from the 34 provinces or municipalities of China. With collaboration with staffs from the local health departments, we made a cluster survey of all the township health centers and the village clinics, and all the village doctors working in the village clinics and about 20 health workers from each township health centers in the five research counties. The interviewers were trained by experienced researchers. In accord with the research design, self-made questionnaires were pre-tested in and modified. We got 1989 copies of Rural Doctor Questionnaire with useful information. Data entering and analysis was accomplished through EpiData 3.1 version and Stata 12.0 version. 


\section{Results}

Of the 1989 respondents, there are $1507(76.035 \%)$ male and 475(23.97\%) female doctors, whose average age was 51.27 years old. Majorities of village doctors took mixed methods (both western medicine and traditional Chinese medicine) to prescript (58.51\%), with the relative low education level (91.22\% doctors with highest degree of the secondary technical school or less). The mean income of village doctors was 1817 (95\% CI, 1733-1900) yuan per month in 2011, with huge inner disparities among different doctor, and among different districts (more than 1000 yuan per month). Only 757(41.3\%) doctors had pensions which show an insufficient social protection, and the self-reported anticipated pension would be 1965yuan per month.

Of the respondents with correct information, 761 (38.45\%) chose west, only 60 (3.03\%) chose TCM, while $1158(58.51 \%)$ chose mixed methods. And $44.61 \%$ of village doctor in Changshu \& Liyang are western style doctors; the ratios of western style doctors in Mianzhu and Yongchuan are almost the same $(41.03 \%$ vs $41.76 \%)$. But only 65 (18.52\%) village doctors in Jingning chose west. However the trends of doctors who chose TCM and mixed methods are opposite to the trend of western style. There are the highest numbers of doctors who chose TCM (3.03\%) and mixed methods $(77.49 \%)$ as their way to practice medicine. The education level of village doctors We also asked about the education level of village doctors that was always treated as the symbol and guarantee of the quality of provided service. Over all, the education level of most village doctors ever gained was Technical secondary school (which is always 3 years' medical training after students graduating from junior high school) or less, consisting of $91.22 \%$. Only 5 people of 1982 get the degree of college or above.

The education level in Jingning is a little higher than other counties and the education level in Changshu \& Liyang is lowest. What's more, the way to gain the highest education level was also interviewed. 1057 (57.14\%) village doctors reported that their highest education degrees were gained after started to work; $793(42.86 \%)$ doctors said that their highest education degree were gained before work. This implies that more than half of the village doctors get their degree through the after-work training.

\section{Discussion}

We can summarize the basic characteristics of village doctors in China as following: aging, gender imbalance[7,8,9], mixed practicing methods, low education level, moderate income and lack of social protection[10, 11,].

\subsection{Aging and gender}

The aging and gender imbalance are not only the unique problems faced by China, but also the world[12,13,]. However, the aging and the gender imbalance are not problems faced by the urban area and urban health institutes, but only the rural $[14,15$, 16]. One possible explanation is that the young have more other better chances to make money, while being a doctor is not a bad choice, which lead more young people supplement the health workforce stock in the lower developed area. The causes of gender imbalance may be more complex. In the east, the gender imbalance is not a real problem, for the 
female village doctors consisted one third of the whole doctors[17, 18].

\subsection{Education}

Education level which means higher educated doctors may tend to be more western style due to more western medicine program in colleges. Unfortunately, this argument seems incorrect for doctors with higher education and younger take use of more mixed methods than older, lower education level doctors. In fact, the village doctors in rural China acted as small businessman competing with other village doctors, private clinics and township healthcare centers after the collective economic collapsed. This implies that the income is based on the technique standard, credit for the local residents, relative competing advantages and local economic development[19].

\subsection{Pension}

During our filed work, the most frequently mentioned thing by the village doctors was the pension, and they told us that they had no pension for not being the employee of the government and having no certification of public employee and the social security system. Our data supports this point of view. Over all, only 757 (41.3\%) doctors had pension, and those doctors with pension were concentrated in which there were special policy to tackle the aging village doctors. The quality of health workforce is not easy to improve so much that satisfy the increasing demand of rural residents due to the aging society, disease transition, universal insurance coverage et al[20].

Without a strong gate-keeper system, the patient had already skipped the local health care facility and jump to the top-level general hospitals which put a big pressure to the whole health system, if the lower tie could not satisfy their need. In a word, the social security system, specially pension play double roles in the health system: let the old doctors safely leave; attract younger doctor to join[21]. We should admit that there are some shortages, for example, respondents tend to underreport their income and over report their expected pension. We might take the more comprehensive and accurate items to detect the reality in the next stage of this project. However, the results of our data are consistent with other research and our fieldwork experience, so we still believe the reliability of the results. Further discussions about the village doctors, village clinics, the township health centers will be introduced on other papers in the future.

\section{Conclusions}

The human resources for health in rural China are enduring obviously aging, gender imbalance, less educating and lacking of protection without deserving priority in the policy making process which might weaken the bottom of China's three-tied health system.Particular well-designed policy and financial support to tackle this potential human resources crisis are needed.

\section{Acknowledgement}

This research was supported by the " 985 " platform project of the Key Technologies of Rural Primary Healthcare funded by Ministry of Science and Technology of China (Number: 2012BAJ18B00). Thanks to the Beijing Normal University, Ministry of Health of China and the health bureau of the 
sampling countries. Thanks also to all the respondents of the project.

\section{References}

(1) Anand S, Fan VY, Zhang J, Zhang L, Ke Y, Dong Z, Chen LC. (2008). China's human resources for health: quantity, quality, and distribution. Lancet 2008, 372(9651):17741781.

(2) Youlong G, Wilkes A, Bloom G. (1997). Health human resource development in rural China. Health policy and planning. 12(4):320-328.

(3) Maru RM. (1977). Health manpower strategies for rural health services in India and China: 1949-1975. Social science \& medicine 1977, 11(10):535-547.

(4) Huiwen $\mathrm{Xu}$, Weijun Zhang et al. (2013). Longitudinal study of rural health workforce in five counties in China: research design and baseline description. Human Resources for Health 2013, 11:17

(5) Zhang D, Unschuld PU. (2008). China's barefoot doctor: past, present, and future. Lancet 2008, 372(9653):1865-1867.

(6) Chen Z (2009). Launch of the health-care reform plan in China. Lancet 2009, 373(9672):1322-1324

(7) Habte D, Dussault G, Dovlo D (2004). Challenges confronting the health workforce in sub-Saharan Africa. World hospitals and health services. The official journal of the International Hospital Federation 2004, 40(2):23-26, 40-21.

(8) Cayley W, Jr. (2009). Continuing challenges to adequate health care workforce in sub-Saharan
Africa. Family Medicine 2009, 41(8):595-596.

(9) Kanchanachitra C, Lindelow M, Johnston T, Hanvoravongchai P, Lorenzo FM, Huong NL, Wilopo SA, dela Rosa JF. (2011). Human resources for health in southeast Asia: shortages, distributional challenges, and international trade in health services. Lancet 2011, 377(9767):769-781.

(10) Rao M, Rao KD, Kumar AK, Chatterjee M, Sundararaman T. (2011). Human resources for health in India. Lancet 2011, 377(9765):587598.

(11) Kuehn BM (2007). Global shortage of health workers, brain drain stress developing countries. JAMA. The journal of the American Medical Association 2007, 298(16):1853-1855.

(12) Staiger DO, Auerbach DI, Buerhaus PI. (2011). Health care reform and the health care workforce--the Massachusetts experience. The New England journal of medicine 2011, 365(12):e24.

(13) Buerhaus PI, Staiger DO, Auerbach DI. (2000). Implications of an aging registered nurseworkforce. JAMA. The journal of the American Medical Association 2000, 283(22):2948-2954.

(14) Cohen JD. (2006). The aging nursing workforce: How to retain experienced nurses. Journal of healthcare management / American College of Healthcare Executives 2006, 51(4):233-245.

(15) Jelfs E. (2012). Workforce issues in European Union health policy. Health services management research . An official journal of the 
Association of University Programs in Health

Administration / HSMC, AUPHA 2012, 25(1):48-49.

(16) Anand S, Fan VY, Zhang J, Zhang L, Ke Y, Dong Z, Chen LC.(2008). China's human resources for health: quantity, quality, and distribution. Lancet 2008, 372(9651):17741781.

(17) Youlong G, Wilkes A, Bloom G (1997). Health human resource development in rural China. Health policy and planning 1997, 12(4):320328.

(18) Chen Z (2009). Launch of the health-care reform plan in China. Lancet 2009, 373(9672):1322-1324.

(19) Meng Q, Xu L, Zhang Y, Qian J, Cai M, Xin Y, Gao J, Xu K, Boerma JT, Barber SL. (2012). Trends in access to health services and financial protection in China between 2003 and 2011. A cross-sectional study. Lancet 2012, 379(9818):805-814.

(20) Yip WC, Hsiao WC, Chen W, Hu S, Ma J, Maynard A. (2012). Early appraisal of China's huge and complex health-care reforms. Lancet 2012, 379(9818):833-842.

(21) Wagstaff A, Yip W, Lindelow M, Hsiao WC. (2009). China's health system and its reform: a review of recent studies. Health economics 2009, 18 Suppl 2:S7- 